\title{
DETERMINAÇÃO DOS CUSTOS DA QUALIDADE EM PRODUÇÃO DE MUDAS DE EUCALIPTO ${ }^{1}$
}

\author{
Helio Garcia Leite ${ }^{2}$, Laércio Antônio Gonçalves Jacovine ${ }^{2}$, Carlos Arthur Barbosa da Silva ${ }^{3}$, Rildo Almeida \\ de Paula ${ }^{4}$ Ismael Eleotério Pires ${ }^{2}$ e Márcio Lopes da Silva ${ }^{2}$
}

\begin{abstract}
RESUMO - Este estudo objetivou determinar os custos da qualidade na produção de mudas de eucalipto em uma empresa que destina sua produção de madeira à fabricação de celulose e papel, situada na Região CentroOeste do Brasil. Os custos da qualidade por atividade e as categorias de custos da qualidade por operação foram obtidos por meio de consultas aos arquivos da empresa, entrevista ao pessoal técnico e operacional e observações "in loco". Pelos levantamentos realizados, pode-se concluir que, apesar de os investimentos em prevenção para a qualidade se encontrarem num bom patamar, os custos de falhas estão altos. Isso pode ser atribuído à falta de avaliação, que impede a determinação do grau de conformidade das várias operações que compõem o processo de produção de mudas, aliado à falta de investimentos em alguns pontos estratégicos de prevenção como treinamento para a qualidade. Os custos de falhas em relação ao custo das mudas representam $7,8 \%$. Era até esperado que esse valor fosse maior, considerando-se a ausência de investimentos em avaliação e em treinamento de pessoal operacional. Tal fato pode ser atribuído à alta qualificação do corpo técnico e aos investimentos em pesquisa. Apesar de esse valor parecer pequeno, quando-se extrapola para o programa anual de 10 milhões de mudas e dependendo do custo real da produção, ele pode representar um valor absoluto considerável.
\end{abstract}

Palavras-chaves: Custos da qualidade, produção de mudas e eucalipto.

\section{DETERMINATION OF QUALITY COSTS IN EUCALYPTUS SEEDLING PRODUCTION}

\begin{abstract}
This study aimed at the determination of quality costs in production of eucalyptus seedlings, in a company that directs its wood production to cellulose and paper manufacturing, located in the Midwestern Brazil. The quality costs per activity and the categories of quality costs per operation were obtained through consultations to the company files, interviews with the technical and operational staff and in loco observations. Through these procedures, it was concluded that in spite of the fact that the investments in prevention for quality are at a good level, the costs of defects are high. This can be attributed to the lack of evaluation, that hinders the determination of the conformity degree of the several operations that comprise the process of seedling production, allied the lack of investments in some strategic points of prevention such as training for enhancing quality. The flaw costs in relation to the seedling cost only represent 7.8\%. This value is relatively low, considering the absence of investments in evaluation and in training of the operational staff. This fact can be attributed to the high qualification of the technical body and the investments in research. Although this value seems small, when it is extrapolated for the annual program of 10 million seedlings, and depending on the real cost of the production, it can represent a considerable amount.
\end{abstract}

Keywords: Quality costs, seedling production and eucalyptus.

\footnotetext{
${ }^{1}$ Recebido em 28.04.2003 e aceito para publicação em 10.08.2005.

${ }^{2}$ Professor Adjunto do Departamento de Engenharia Florestal da UFV. 36570-000 Viçosa-MG.

${ }^{3}$ Professor Titular do Departamento de Tecnologia de Alimentos da UFV. 36570-000 Viçosa-MG.

${ }^{4}$ Engenheiro Florestal.
} 


\section{INTRODUÇÃO}

Atualmente, as empresas estão no limiar de uma nova era, a da "qualidade", em que o desperdício será penalizado. Há o início da consciência da importância do aproveitamento total de material, e a ordem é fazer certo na primeira vez (ROBLES JR., 1994). Até alguns governos, através de incentivos às empresas, têm motivado a utilização, reciclagem e aproveitamento de toda a matéria-prima. Essas iniciativas, muitas vezes, baseiam-se na preservação e preocupação ecológica. Além do mais, em muitos casos a qualidade toma o sentido de produtividade, pois reduz retrabalho e desperdícios.

Hoje, mais do que nunca, qualidade é questão de sobrevivência; a qualidade do produto é que mantém as empresas no mercado em condições de competir. Daí a grande necessidade de saber quanto custa, ou quanto se deixa de ganhar, com a qualidade ou pela falta desta em um produto, pois isso vai refletir diretamente a aceitação e o seu valor final.

O êxito de um reflorestamento depende de muitos fatores, entre eles a qualidade das mudas levadas ao campo, que, além de resistirem às condições adversas, devem ser capazes de desenvolver produzindo árvores com crescimento satisfatório (PAIVA e GOMES, 1995; GONÇALVES et al., 2004).

Em um projeto de reflorestamento, a qualidade das mudas é muito importante, por estar relacionada diretamente com a qualidade do povoamento por ocasião da colheita final. Por se tratar de investimentos de longo prazo, o rigor torna-se maior, justificando o dispêndio com a qualidade das mudas e com o controle contínuo dos custos da qualidade.

A determinação dos custos da qualidade no caso da produção de mudas permite: avaliar os programas de qualidade por intermédio de quantificações físicas e monetárias; levantar novos objetivos para os programas de qualidade, priorizando aqueles que tragam melhores resultados para a empresa; tornar a qualidade um dos objetivos estratégicos para a empresa, pois, segundo Robles Jr.(1994), o Custo da Qualidade é um dos elementos fundamentais da Gestão Estratégica de uma Empresa; facilitar a elaboração do orçamento de custos da qualidade, permitindo a adequada alocação dos recursos; conhecer quanto a empresa vem investindo nas diferentes categorias de custos da qualidade (prevenção, avaliação, falhas internas e falhas externas) e inferir sobre quanto deveria ser investido em cada categoria; facilitar a avaliação do efeito da qualidade no custo e valor das mudas; facilitar o monitoramento para a obtenção de dados seqüenciais de custos da qualidade, assim como a correta fixação, definição e transparência dos indicadores de qualidade.

Diante do exposto, realizou-se este estudo com o objetivo de determinar os custos da qualidade, em produção de mudas de Eucalyptus spp. por propagação vegetativa.

\section{MATERIAL E MÉTODOS}

O trabalho foi realizado a partir de dados obtidos em um viveiro de produção de mudas de eucalipto, de uma empresa de grande porte e tradicional do setor de Celulose e Papel, localizada na Região Centro-Oeste do Brasil, a qual produz 100 por cento de suas mudas por propagação vegetativa, com mão-de-obra própria e pessoal técnico altamente qualificado.

\subsection{Descrição das categorias de custos da qualidade}

Buscou-se na fase inicial identificar os custos por atividade e as categorias de custos da qualidade por operação, através de consultas aos arquivos da empresa, entrevista ao pessoal técnico e operacional e observações "in loco".

A definição e caracterização das categorias de custos da qualidade por operação foram feitas a partir de sua identificação na primeira fase e enquadramento das normas técnicas da empresa, com a participação do seu pessoal (pessoal de viveiro, plantio, departamento de compras, almoxarifado, pesquisa, treinamento e gerência), e, ainda, levantamentos "in loco".

A quantificação dos custos por categorias, dentro de cada operação, foi feita através de consultas aos arquivos de custos, acompanhamento operacional/ amostragens, desde a solicitação de compras de insumos até a expedição das mudas, a partir de metodologia definida, juntamente com o corpo técnico da empresa para que não houvesse transtornos nas operações a serem avaliadas.

Foram identificadas as quatro categorias de custos, seguindo-se a classificação de Juran e Gryna (1991):

Custos de prevenção: são aqueles com atividades que procuram evitar produtos defeituosos.

Custos de avaliação: são aqueles incorridos na determinação do grau de conformidade com os requisitos de qualidade. 
Custos das falhas internas: custos associados aos defeitos encontrados antes da transferência do produto ao consumidor.

Custos das falhas externas: custos gerados por problemas ocorridos após a entrega do produto ao cliente, estando associados a reclamações dos clientes e devoluções, entre outros.

Como a produção de mudas é destinada à própria empresa, os custos de falhas externas do viveiro foram consideradas como falhas internas e, por questões operacionais, computados apenas os custos de falhas, não havendo a preocupação em separar em falhas internas e externas.

A partir de reuniões, observações e consultas bibliográficas, chegou-se aos itens que comporiam cada categoria de custos da qualidade, tanto para operações de apoio quanto para as de produção de mudas.

\subsubsection{Operações de apoio}

São aquelas que envolvem atividades necessárias ao funcionamento do viveiro, mas que não estão diretamente envolvidas na produção de mudas, como o setor de suprimentos - aquisição, armazenagem e distribuição de insumos.

Devido à sua maior participação, foram consideradas operações de apoio, com as respectivas categorias de custos da qualidade, as seguintes:

a) Aquisição de Insumos (compras e recepção)

*Custos de prevenção - Normatização dos procedimentos do Departamento de Compras; Treinamento de pessoal do Departamento de Compras e viveiro relacionado aos pedidos de insumos, como preenchimento de formulários, como fazer pesquisas de mercado e auditorias; Análise do fornecedor: verificação da sua capacidade para cumprir requisitos da qualidade, através de pesquisa de mercado; de Auditoria do fornecedor: avaliação "in loco" de sua "performance" real, como: qualidade do produto, garantia, custo e condições de pagamento e de atender à demanda.

*Custos de avaliação - Inspeção, amostragens e testes de recebimento de materiais, como testes de germinação e amostragens de adubos para análise, entre outras.

*Custos de falhas - Seleção de material rejeitado pela inspeção de recebimento, incluindo manuseio e transporte; Substituição de material: devolução e transporte e custos adicionais; Retrabalho em rejeitados fornecidos fora da faixa técnica ou que não tenha sido inspecionado na recepção; e Perdas de materiais por manuseio inadequado na recepção ou sem aproveitamento por erro de aquisição.

b) Almoxarifado (armazenamento e distribuição de insumos)

*Custos de prevenção - Normatização dos procedimentos de almoxarifado para armazenagem e distribuição de insumos de viveiro; Treinamento de pessoal, objetivando a qualidade de atendimento ao viveiro; e Aquisição e manutenção de equipamentos e locais utilizados para armazenamento, com o objetivo de melhorar a qualidade.

*Custos de avaliação - Análise e testes periódicos para certificação da qualidade dos insumos armazenados e das condições de armazenamento.

*Custos de falhas - Material danificado por manuseio e condições inadequadas de armazenamento; Material estragado por ausência de critério na expedição (ex.: data de validade vencida, enquanto já foi utilizado material mais novo); Perdas de equipamentos utilizados para armazenagem por falta de manutenção; Demora na distribuição do material solicitado, incorrendo em perdas por deixar de produzir - perdas de produção; e Distribuição de material errado, incorrendo em perdas de produção e transporte de volta, entre outras.

\subsubsection{Operações de produção}

Estas operações são aquelas diretamente envolvidas no processo de produção de mudas, desde a compostagem e jardim clonal até a expedição das mudas para o plantio.

No Quadro 1, sumariza-se a classificação dos custos da qualidade por operação, de forma a mostrar onde é possível ocorrer aquele tipo de custo.

Nas avaliações, procurou-se trabalhar com amostragens representativas e repetidas, em mais de um dia de produção, de forma a obter mais confiabilidade nos dados e testar a consistência da metodologia.

Um dos maiores problemas no estudo de custos da qualidade é justamente a quantificação exata dos valores, uma vez que os erros têm o efeito cascata, dificultando a determinação do quanto se perde na

R. Árvore, Viçosa-MG, v.29, n.6, p.955-964, 2005 
seqüência por uma falha anterior. Tratando-se de produção de mudas, isso se torna muito mais difícil, pois muitas falhas levam a perda da muda ou distúrbios fisiológicos para os quais não se sabe exatamente os prejuízos futuros, pois se espera uma floresta para no mínimo 12 anos ( 2 cortes), nunca se esquecendo de que uma muda sem qualidade, ou morta, poderia ser a árvore de amanhã.

Outra grande dificuldade é quantificar o porcentual do custo do desenvolvimento de uma pesquisa que deve ser alocado por unidade, já que esta pesquisa poderá ser utilizada por muitos anos, ou seja, em quanto tempo se deve amortizar os custos da pesquisa.

Mesmo com as dificuldades explicitadas foi possível estimar para algumas operações os custos de falhas, através da quantificação da perda de recursos como insumos e mão-de-obra.

Padronizou-se que todos os custos seriam apresentados, sempre pela mesma unidade, e a mais comum para o caso em estudo é "Mil Mudas - MM", porém, como em certas fases do processo não se têm mudas, trabalha-se com suas variações, "Mil Tubetes -MT" e "Mil Estacas - ME", que irão compor da mesma forma os custos. Por ocasião do estudo, a relação dólar/ real era a seguinte: US\$ $1=\mathrm{R} \$ 1,09$.

\section{RESULTADOS E DISCUSSÃO}

A partir da aplicação dos dados porcentuais da participação das operações (Quadro 2) no custo total de produção de mudas foi possível determinar os custos de cada uma delas, de forma a captar todos os seus componentes (Quadro 3). Com isso, ao calcular as perdas com determinada operação já estão embutidas todas as despesas que a compõem, como encargos, administração, manutenção e insumos como adubos, defensivos etc., inclusive os gastos com prevenção. O custo total da produção de mudas considerado foi de $\mathrm{R} \$ 100,00$ (cem reais).

Tabela 1 - Classificação dos custos da qualidade nas diferentes operações de produção de mudas de Eucalyptus spp. por propagação vegetativa Table 1 - Classification of the quality costs for the different operations of Eucalyptus spp. seedling production through vegetative propagation

\begin{tabular}{|c|c|c|c|c|c|c|c|c|c|c|c|c|}
\hline \multirow[t]{2}{*}{$\overline{\text { Custos }}$} & \multicolumn{12}{|c|}{ Operações } \\
\hline & 1 & 2 & 3 & 4 & 5 & 6 & 7 & 8 & 9 & 10 & 11 & 12 \\
\hline \multicolumn{13}{|l|}{ 1. Prevenção } \\
\hline Treinamento para qualidade & $\mathrm{X}$ & $\mathrm{X}$ & $\mathrm{X}$ & $\mathrm{X}$ & $\mathrm{X}$ & $\mathrm{X}$ & $\mathrm{X}$ & $\mathrm{X}$ & $\mathrm{X}$ & $\mathrm{X}$ & $\mathrm{X}$ & $\mathrm{X}$ \\
\hline CEP - Horas de levantamento e análise, e material & $\mathrm{X}$ & $\mathrm{X}$ & $\mathrm{X}$ & $\mathrm{X}$ & $\mathrm{X}$ & $\mathrm{X}$ & $\mathrm{X}$ & $\mathrm{X}$ & $\mathrm{X}$ & $\mathrm{X}$ & $\mathrm{X}$ & $\mathrm{X}$ \\
\hline $\begin{array}{l}\text { Testes e experimentos para o desenvolvimento } \\
\text { de novas técnicas e enquadramento nas normas técnic }\end{array}$ & $\begin{array}{r}X \\
\text { cas }\end{array}$ & $\mathrm{X}$ & $\mathrm{X}$ & $\mathrm{X}$ & $\mathrm{X}$ & $\mathrm{X}$ & $\mathrm{X}$ & $\mathrm{X}$ & $\mathrm{X}$ & $\mathrm{X}$ & $\mathrm{X}$ & $\mathrm{X}$ \\
\hline $\begin{array}{l}\text { Testes para determinação da periodicidade da } \\
\text { regulagem de equipamentos }\end{array}$ & $X$ & $X$ & $X$ & $X$ & $X$ & $\mathrm{X}$ & $X$ & $\mathrm{X}$ & $X$ & $X$ & $X$ & $\mathrm{X}$ \\
\hline Operações desenvolvidas para obtenção da qualidade & $X$ & $\mathrm{X}$ & $\mathrm{X}$ & $\mathrm{X}$ & $\mathrm{X}$ & $\mathrm{X}$ & $\mathrm{X}$ & $\mathrm{X}$ & $\mathrm{X}$ & $X$ & $\mathrm{X}$ & $\mathrm{X}$ \\
\hline $\begin{array}{l}\text { Inspeção, testes e auditorias de produção, } \\
\text { rotineiras ou não }\end{array}$ & $\mathrm{X}$ & $\mathrm{X}$ & $\mathrm{X}$ & $\mathrm{X}$ & $X$ & $\mathrm{X}$ & $\mathrm{X}$ & $\mathrm{X}$ & $\mathrm{X}$ & $\mathrm{X}$ & $\mathrm{X}$ & $X$ \\
\hline $\begin{array}{l}\text { Inspeção e testes set-up: para assegurar o correto } \\
\text { ajuste de máquinas e equipamentos }\end{array}$ & $\mathrm{X}$ & $\mathrm{X}$ & $\mathrm{X}$ & $\mathrm{X}$ & $\mathrm{X}$ & $\mathrm{X}$ & $\mathrm{X}$ & $\mathrm{X}$ & $\mathrm{X}$ & $\mathrm{X}$ & $\mathrm{X}$ & $\mathrm{X}$ \\
\hline Laboratórios e equipamentos & $\mathrm{X}$ & $\mathrm{X}$ & $\mathrm{X}$ & $\mathrm{X}$ & $\mathrm{X}$ & $\mathrm{X}$ & $\mathrm{X}$ & $\mathrm{X}$ & $X$ & $\mathrm{X}$ & $\mathrm{X}$ & $\mathrm{X}$ \\
\hline $\begin{array}{l}\text { Reparo ou retrabalho de operação em } \\
\text { produtos não-conformes }\end{array}$ & $X$ & $\mathrm{X}$ & $\mathrm{X}$ & $\mathrm{X}$ & $X$ & $\mathrm{X}$ & $\mathrm{X}$ & $\mathrm{X}$ & $X$ & $X$ & $\mathrm{X}$ & $\mathrm{X}$ \\
\hline Sucata (perda total) & $\mathrm{X}$ & $\mathrm{X}$ & $\mathrm{X}$ & $\mathrm{X}$ & $\mathrm{X}$ & $\mathrm{X}$ & $\mathrm{X}$ & $\mathrm{X}$ & $\mathrm{X}$ & $\mathrm{X}$ & $\mathrm{X}$ & $\mathrm{X}$ \\
\hline Re-Inspeção e re-teste & $\mathrm{X}$ & $\mathrm{X}$ & $\mathrm{X}$ & $\mathrm{X}$ & $\mathrm{X}$ & $\mathrm{X}$ & $\mathrm{X}$ & $\mathrm{X}$ & $\mathrm{X}$ & $\mathrm{X}$ & $\mathrm{X}$ & $\mathrm{X}$ \\
\hline Perdas de trabalho devido a falhas internas & $\mathrm{X}$ & $\mathrm{X}$ & $\mathrm{X}$ & $\mathrm{X}$ & $\mathrm{X}$ & $\mathrm{X}$ & $\mathrm{X}$ & $\mathrm{X}$ & $\mathrm{X}$ & $\mathrm{X}$ & $\mathrm{X}$ & $\mathrm{X}$ \\
\hline Análise das falhas & $\mathrm{X}$ & $\mathrm{X}$ & $\mathrm{X}$ & $\mathrm{X}$ & $\mathrm{X}$ & $\mathrm{X}$ & $\mathrm{X}$ & $\mathrm{X}$ & $\mathrm{X}$ & $\mathrm{X}$ & $\mathrm{X}$ & $\mathrm{X}$ \\
\hline \multicolumn{13}{|l|}{ 4. Falhas Externas } \\
\hline Investigação de queixas no plantio & - & - & - & - & - & - & - & - & - & - & - & $\mathrm{X}$ \\
\hline $\begin{array}{l}\text { Mudas retornadas: transporte, avaliação, } \\
\text { reparo e substituição, sucata }\end{array}$ & - & - & - & - & - & - & - & - & - & - & - & $X$ \\
\hline $\begin{array}{l}\text { Transtornos devido a falhas internas de } \\
\text { viveiro, como: horas paradas }\end{array}$ & - & - & - & - & - & - & - & - & - & - & - & $X$ \\
\hline
\end{tabular}

Operações: 1-compostagem, 2-coleta de brotação, 3-desinfecção de tubetes, 4-enchimento de tubetes, 5-encanteiramento, 6-confecção de estacas, 7-transporte para casa de vegetação, 8-estaqueamento, 9-reencanteiramento, 10-remoção/classificação, 11-toilet/classificação e 12-expedição.

R. Árvore, Viçosa-MG, v.29, n.6, p.955-964, 2005 
Tabela 2 - Rendimentos operacionais, hora/homem (HH) por mil tubetes, estacas ou mudas (HH/mil) e participação porcentual por operação

Table 2 - Operational productivity, hour/man (HH) per thousand tubes, cutting or seedlings (HH/thousand), and percent participation per operation

\begin{tabular}{lccc}
\hline \multicolumn{1}{c}{ Operação } & \multicolumn{2}{c}{ PH/mil } & \multicolumn{2}{c}{ Participação (\%) } & Operação \\
\cline { 2 - 4 } & Operação & Acumulado & 3,21 \\
\hline Compostagem & 0,278 & 0,278 & 3,21 \\
Coleta de brotação & 0,286 & 0,564 & 6,52 \\
Desinfecção de tubetes & 0,118 & 0,682 & 1,36 \\
Enchimento de tubetes & 0,608 & 1,290 & 7,03 \\
Encanteirar & 0,174 & 1,464 & 2,01 \\
Confecção de estacas & 2,941 & 4,405 & 34,01 \\
Transporte de estacas para C.V. & 0,083 & 4,488 & 0,96 \\
Estaqueamento & 0,826 & 5,314 & 9,55 \\
Reencanteiramento & 0,167 & 5,481 & 1,93 \\
Remoção/classificação & 0,667 & 6,148 & 5,93 \\
Classificação/Toilet & 2,000 & 8,148 & 51,90 \\
Expedição & 0,500 & 8,648 & 61,45 \\
\hline
\end{tabular}

Tabela 3 - Composição dos custos de viveiro, mediante a distribuição porcentual pelas principais operações Table 3 - Composition of the nursery costs, by percent distribution per main operations

\begin{tabular}{|c|c|c|c|c|c|c|c|c|c|c|c|c|c|c|c|}
\hline \multirow{3}{*}{ Item } & \multirow[t]{3}{*}{ Despesas } & \multirow{3}{*}{$\begin{array}{c}\text { Composição } \\
\text { \% dos } \\
\text { Custos }\end{array}$} & \multirow{3}{*}{$\begin{array}{l}\text { Categ } \\
\text { de } \\
\text { Custo }\end{array}$} & \multicolumn{12}{|c|}{ Custo por Operação (R\$MM) } \\
\hline & & & & 1 & 2 & 3 & 4 & 5 & 6 & 7 & 8 & 9 & 10 & 11 & 12 \\
\hline & & & & $3,21 \%$ & $3,31 \%$ & $1,36 \%$ & $7,03 \%$ & $2,01 \%$ & $34,01 \%$ & $0,96 \%$ & $9,55 \%$ & $1,93 \%$ & $7,71 \%$ & $23,13 \%$ & $5,78 \%$ \\
\hline 1 & Mão-de-obra(salário) & 25,21 & CAN & 0,81 & 0,83 & 0,34 & 1,77 & 0,51 & 8,57 & 0,24 & 2,41 & 0,49 & 1,94 & 5,83 & 1,46 \\
\hline 2 & Encargos sociais & 13,25 & CAN & 0,43 & 0,44 & 0,18 & 0,93 & 0,27 & 4,51 & 0,13 & 1,27 & 0,26 & 1,02 & 3,07 & 0,77 \\
\hline 3 & Material de segurança & 1,15 & $\mathrm{CAN}$ & 0,04 & 0,04 & 0,02 & 0,08 & 0,02 & 0,39 & 0,01 & 0,11 & 0,02 & 0,09 & 0,27 & 0,07 \\
\hline 4 & Transporte pessoal & 5,12 & CAN & 0,16 & 0,17 & 0,07 & 0,36 & 0,10 & 1,74 & 0,05 & 0,49 & 0,10 & 0,39 & 1,18 & 0,30 \\
\hline 5 & Convênio médico & 2,43 & CAN & 0,08 & 0,08 & 0,03 & 0,17 & 0,05 & 0,82 & 0,02 & 0,23 & 0,05 & 0,19 & 0,56 & 0,14 \\
\hline 6 & Cesta básica & 2,79 & CAN & 0,09 & 0,09 & 0,04 & 0,20 & 0,06 & 0,95 & 0,03 & 0,27 & 0,05 & 0,22 & 0,65 & 0,16 \\
\hline 7 & Empreiteiros (mão-de-obra) & 1,76 & CAN & 0,06 & 0,06 & 0,02 & 0,12 & 0,04 & 0,60 & 0,02 & 0,17 & 0,03 & 0,14 & 0,41 & 0,10 \\
\hline 8 & Substrato & 1,39 & CAN & 0,04 & 0,05 & 0,02 & 0,10 & 0,03 & 0,47 & 0,01 & 0,13 & 0,03 & 0,11 & 0,32 & 0,08 \\
\hline 9 & Fertilizantes & 0,72 & CAN & 0,02 & 0,02 & 0,01 & 0,05 & 0,01 & 0,25 & 0,01 & 0,07 & 0,01 & 0,06 & 0,17 & 0,04 \\
\hline 10 & Defensivos agrícolas & 0,42 & CAN & 0,01 & 0,01 & 0,01 & 0,03 & 0,01 & 0,14 & 0,00 & 0,04 & 0,01 & 0,03 & 0,10 & 0,02 \\
\hline 11 & Material de consumo & 1,01 & CAN & 0,03 & 0,03 & 0,01 & 0,07 & 0,02 & 0,34 & 0,01 & 0,10 & 0,02 & 0,08 & 0,23 & 0,06 \\
\hline 12 & Material de manutenção & 3,08 & CAN & 0,10 & 0,10 & 0,04 & 0,22 & 0,06 & 1,05 & 0,03 & 0,29 & 0,06 & 0,24 & 0,71 & 0,18 \\
\hline 13 & Despesas administrativas & 0,31 & CAN & 0,01 & 0,01 & 0,00 & 0,02 & 0,01 & 0,11 & 0,00 & 0,03 & 0,01 & 0,02 & 0,07 & 0,02 \\
\hline 14 & Depreciação & 14,86 & CAN & 0,48 & 0,49 & 0,20 & 1,04 & 0,30 & 5,05 & 0,14 & 1,42 & 0,29 & 1,15 & 3,44 & 0,86 \\
\hline 15 & Assessoria de planejamento & to 4,03 & CAN & 0,13 & 0,13 & 0,05 & 0,28 & 0,08 & 1,37 & 0,04 & 0,38 & 0,08 & 0,31 & 0,93 & 0,23 \\
\hline 16 & Assessoria de pesquisa & 5,12 & PV & 0,16 & 0,17 & 0,07 & 0,36 & 0,10 & 1,74 & 0,05 & 0,49 & 0,10 & 0,40 & 1,18 & 0,30 \\
\hline 17 & Administração indireta & 2,02 & CAN & 0,06 & 0,07 & 0,03 & 0,14 & 0,04 & 0,69 & 0,02 & 0,19 & 0,04 & 0,16 & 0,47 & 0,12 \\
\hline 18 & Oficinas & 1,36 & CAN & 0,04 & 0,04 & 0,02 & 0,10 & 0,03 & 0,46 & 0,01 & 0,13 & 0,03 & 0,10 & 0,31 & 0,08 \\
\hline 19 & Veículos & 0,04 & CAN & 0,00 & 0,00 & 0,00 & 0,00 & 0,00 & 0,01 & 0,00 & 0,00 & 0,00 & 0,00 & 0,01 & 0,00 \\
\hline 20 & Mecanização & 4,37 & CAN & 0,14 & 0,14 & 0,06 & 0,31 & 0,09 & 1,49 & 0,04 & 0,42 & 0,08 & 0,34 & 1,01 & 0,25 \\
\hline 21 & Restaurante & 3,82 & CAN & 0,12 & 0,13 & 0,05 & 0,27 & 0,08 & 1,30 & 0,04 & 0,37 & 0,07 & 0,29 & 0,88 & 0,22 \\
\hline 22 & Medicina do trabalho & 1,72 & CAN & 0,06 & 0,06 & 0,02 & 0,12 & 0,03 & 0,59 & 0,02 & 0,16 & 0,03 & 0,13 & 0,40 & 0,10 \\
\hline 23 & Segurança do trabalho & 1,53 & CAN & 0,05 & 0,05 & 0,02 & 0,11 & 0,03 & 0,52 & 0,01 & 0,15 & 0,03 & 0,12 & 0,35 & 0,09 \\
\hline 24 & Segurança patrimonial & 1,15 & CAN & 0,04 & 0,04 & 0,02 & 0,08 & 0,02 & 0,39 & 0,01 & 0,11 & 0,02 & 0,09 & 0,27 & 0,07 \\
\hline 25 & Amoxarifado & 0,38 & CAN & 0,01 & 0,01 & 0,01 & 0,03 & 0,01 & 0,13 & 0,00 & 0,04 & 0,01 & 0,03 & 0,09 & 0,02 \\
\hline \multirow[t]{2}{*}{26} & Outros & 0,96 & CAN & 0,03 & 0,03 & 0,01 & 0,07 & 0,02 & 0,33 & 0,01 & 0,09 & 0,02 & 0,07 & 0,22 & 0,06 \\
\hline & TOTAL & 100,00 & & 3,21 & 3,31 & 1,36 & 7,03 & 2,01 & 34,01 & 0,96 & 9,55 & 1,93 & 7,71 & 23,13 & 5,78 \\
\hline
\end{tabular}

Operações: 1-compostagem, 2-coleta de brotação, 3-desinfecção de tubetes, 4-enchimento de tubetes, 5-encanteiramento, 6-confecção de estacas, 7-transporte para casa de vegetação, 8-estaqueamento, 9-reencanteiramento, 10-remoção/classificação, 11-toilet/classificação, 12-expedição e CAN - Custo da atividade normal. 
Apenas custos da atividade normal (CAN), segundo Douchy (1992), são aqueles necessários e suficientes para realizar bem um trabalho; custos de prevenção (PV) são observados no Quadro 3. Porém, isso não significa que não existam outras categorias, principalmente custos de falhas que, na maioria das vezes, não são computados, mas encobertos pelos rendimentos, sendo seus valores absorvidos em custos de materiais, mão-de-obra e outros.

Nos custos de mão-de-obra, consideraram-se: salários, encargos sociais, materiais de segurança, transporte pessoal, convênio médico, cesta básica, empreiteiros (pessoal operacional), restaurante e medicina e segurança do trabalho, dividindo-os pelos recursos humanos despendidos. Esses são os custos que incidem diretamente sobre as despesas com pessoal, representando $58,8 \%$ do custo total de produção de mudas, conforme pode ser observado no Quadro 3.

\subsection{Custos de Prevenção}

Os custos de prevenção encontrados foram apenas aqueles relacionados com Assessoria de Pesquisa (Quadro 3), devido ao trabalho de desenvolvimento de novas técnicas para melhoria de processos, como:

- Desenvolvimento de novas técnicas para obtenção da qualidade.

- Normatização.

- Controle de processos.

Os custos relacionados a esses itens perfazem um total de 5,12 R\$/MM (Quadro 3).

\subsection{Custos de Avaliação}

No estudo de caso realizado, detectou-se que a empresa não investe em avaliação, o que pode comprometer a qualidade, pois o acompanhamento através da avaliação de processos é fundamental para que se evitem falhas.

Com o total de prevenção mais avaliação, podese totalizar o que a empresa investe em custos de conformidade, que são aqueles objetivando que se faça certo da primeira vez.

\subsection{Custos de Falhas}

Neste estudo não foi possível a quantificação das falhas externas ao processo devido a questões operacionais. Portanto, os custos de falhas apresentados são apenas de falhas internas ao processo de produção de mudas.
A partir de observações e dos questionários aplicados às pessoas envolvidas na produção de mudas, foi possível verificar onde poderiam estar as falhas possíveis de quantificação monetária, mesmo que estas sejam parciais.

\subsubsection{Coleta de brotação}

A constante modificação do planejamento fez que o jardim clonal se tornasse subdimensionado, portanto com a produção insuficiente para atender à demanda de produção de mudas. Com isso, tornou-se necessária a utilização de áreas, antes experimentais, distantes do viveiro, para coleta de brotação.

A partir das distâncias atuais entre o viveiro e essas áreas de produção, pode-se calcular a distância média para que seja possível determinar quanto a mais é preciso se deslocar para obter de brotação.

Fazendo uma média aritmética simples, obtevese uma distância média de $11,2 \mathrm{~km}$ de ida e volta entre viveiro e área de coleta no campo, contra $0,8 \mathrm{~km}$ de ida e volta do jardim clonal.

Utilizando apenas os dados disponíveis, podemse fazer algumas considerações:

- Conjugando o custo do $\mathrm{km}$ rodado do veículo utilizado $(\mathrm{R} \$ 0,36)$ com as respectivas distâncias médias, tem-se que o custo por viagem ao viveiro é de $\mathrm{R} \$ 0,29$ para o jardim clonal e de $\mathrm{R} \$ 4,03$ para o campo, ou seja, aproximadamente 14 vezes mais caro.

- A partir dos dados do número de touças por hectare e de estacas por touça, pode-se verificar que a área necessária é 1,7 vez maior para a produção no campo do que no jardim clonal, e sabe-se que, quando uma área disponível não é utilizada para produção comercial, é menor a produção, exigindo aquisição de mais terras para plantio e suprimento da demanda da fábrica.

- O ambiente parcialmente controlado pode evitar problemas que possam vir acontecer, como geadas, secas prolongadas e ocorrência de pragas e doenças, entre outras, favorecendo o cumprimento do cronograma.

- Seriam necessários dados de custos de manutenção do jardim clonal e área de produção no campo, para efetuar análises mais profundas, porém esses dados não foram obtidos.

\subsubsection{Enchimento de tubetes}

Como os tubetes são reaproveitados por vários anos, e não é feito uma seleção rigorosa quanto ao seu estado de conservação, observou-se queda constante 
destes durante as várias operações que se seguem no processo, desde seu enchimento até a expedição das mudas, principalmente pela falta das bordas.

Para a quantificação da queda de tubetes, coletouse no final de um dia de produção aqueles que caíram das bandejas, durante o enchimento.

Para uma produção de 94.688 tubetes, caíram 576 tubetes, o equivalente a $0,6 \%$.

Utilizando os custos de mão-de-obra, pois o substrato que cai é reaproveitado, perde-se o equivalente à desinfecção e enchimento dos tubetes. Conforme apresentado no Quadro 3, os itens desinfecção de tubetes e enchimento de tubetes representam um custo total de 8,39 R\$/MT.

Como a perda é $0,6 \%$ e o dispêndio é de 8,39 $\mathrm{R} \$ / \mathrm{MT}$, perde-se 0,05118 R \$/MT.

\subsubsection{ENCANTEIRAMENTO}

Nesta operação foram verificados dois pontos quantificáveis monetariamente: a queda de tubetes, cujo motivo já foi mencionado no item anterior, e a perda de vermiculita ao transportar, encanteirar e completar as bandejas.

\section{a) Queda de tubetes}

Para a quantificação foram separados quatro canteiros, em dois dias de produção, sendo um no primeiro dia e três no segundo, que, após estaqueados, coletaramse os tubetes caídos e procedeu-se à contagem, sendo em um dos canteiros contados antes do estaqueamento.

Em cada canteiro de 50.688 mil tubetes caem em média 130,55 tubetes, após encanteirado e estaqueado, o que equivale a $0,26 \%$. Considerando apenas encanteiramento, caem em média 42 tubetes por canteiro, equivalendo a $0,08 \%$. Portanto, o estaqueamento contribui para a queda do tubete, o que já era esperado, devido a força que é aplicada ao tubete no momento do estaqueamento.

Percebe-se que, à medida que o tubete vai passando por etapas do processo, ele vai se tornando mais caro, pois se adicionam trabalho e material.

Nesse caso, os seguintes custos foram considerados: coleta de brotação, desinfecção de tubetes, enchimento de tubetes, encanteiramento, confecção de estacas, transporte de estacas para casa de vegetação e estaqueamento. Conforme apresentado no Quadro 3 , os custos relacionados a esses itens correspondem a um total de 58,23 R\$/MT.

No caso da amostra realizada antes do estaqueamento, a perda refere-se apenas às operações de desinfecção, enchimento de tubetes e encanteiramento. Como as perdas no caso é de $0.08 \%$ e o total dispendido é de $10,40 \mathrm{R} \$ /$ MT, tem-se uma perda de 0,00832 R \$/MT até os tubetes estarem prontos para receber as estacas. Considerando as perdas de $0,26 \%$ após o estaqueamento e um total de dispêndio de 58,23 R\$/MT, as perdas até então totalizam 0,15140 R\$/MT.

b) Perda de vermiculita

Devido à movimentação das bandejas, e ao fato de estas estarem com excesso de vermiculita, notouse uma grande perda desse material debaixo dos canteiros durante o encanteiramento. Essa perda é uma falha, que exige uma operação de retrabalho, já incorporada pela equipe técnica, que é a complementação dos tubetes com vermiculita, e seu excesso deixado nas bandejas durante a operação também demonstrou representar uma quantidade expressiva. A partir dessas observações, procurou-se a quantificação dessas perdas.

Para isso foram amostrados dois canteiros, nos quais se colocaram sob eles lonas plásticas para a coleta, nas duas extremidades e no meio. Após o término da operação, a vermiculita que caiu sobre as lonas foi medida e essa quantidade, extrapolada para os dois canteiros. Com esse total, obteve-se a perda de vermiculita para MT, sendo o resultado igual a 0,69 L de vermiculita/ MT.

No caso da vermiculita excedente nas beiradas dos canteiros, coletou-se em três canteiros completos, nas duas bordas, e em seguida dividiu-se esse total pela capacidade dos canteiros, obtendo uma perda de $0,09 \mathrm{~L}$ de vermiculita/MT, num total de $0,78 \mathrm{~L} / \mathrm{MT}$.

O consumo de vermiculita pura (camada superior do tubete), que representa $30 \%$ do conteúdo do tubete e $35 \%$ do custo do substrato, é de $0,017 \mathrm{~m}^{3} / \mathrm{MM}$ (17 litros/MM), a um custo de R\$0,00025/MM.

Ao perder $0,78 \mathrm{~L}$ de vermiculita/MT, perdem-se $4,58 \%$, equivalendo a $0,00001 \mathrm{R} \$ / \mathrm{MM}$.

Deve-se notar que não foram quantificadas as perdas com fungicidas, horas de mão-de-obra para retrabalho - de difícil quantificação, uma vez que estas ficam

R. Árvore, Viçosa-MG, v.29, n.6, p.955-964, 2005 
embutidas nos rendimentos operacionais de outras operações - nem o valor da estaca, assim como transporte do jardim clonal ou campo até o viveiro, adubos etc. Há também as perdas de difícil mensuração. Por exemplo, o excesso de vermiculita no piso da casa de vegetação deixa o ambiente favorável ao desenvolvimento biológico, o que contribui negativamente para o controle fitossanitário.

Somando os custos levantados para a operação de encanteiramento, tem-se uma perda de $0,15141 \mathrm{R} \$ / \mathrm{MT}$.

\subsubsection{Preparação de estacas}

A partir do momento que as estacas chegam ao viveiro, estas devem ser aproveitadas ao máximo, pois os custos embutidos nessas são altos, uma vez que vem de um programa de melhoramento, na maioria das vezes, de longos anos de estudo.

Observou-se que no lixo produzido na confecção das estacas havia muitas que poderiam ter sido aproveitadas. Para a quantificação destas, avaliaramse dois dias de produção, com a ressalva de que, no primeiro dia, para uma produção total de 101 mil estacas, amostrou-se o lixo de uma produção de 5.300 estacas, detectou-se um desperdício de 352 estacas, equivalente a $6,2 \%\{[352 /(5300+352)] \times 100\}$. No segundo dia, para uma produção total de $50 \mathrm{mil}$ estacas amostrou-se o lixo de 2.319 estacas, com um desperdício de 222 unidades, equivalente a $8,7 \%$. A média dos dois dias foi de 7,0\% do material.

Considerando os custos para coleta de brotação e confecção de estacas, apresentados no Quadro 3, tem-se um total de 10,11 R\$/ME.

No cálculo do custo de confecção de estacas foram considerados apenas $20 \%$ do rendimento da operação, pois as estacas não foram confeccionadas, mas consumiram mão-de-obra envolvida na operação, bem como para abastecimento da banca, limpeza etc.

Com a perda de 7,0\% e um dispêndio de 10,11 $\mathrm{R} \$ / \mathrm{ME}$, perde-se 0,70871 R\$/ME.

\subsubsection{Remoção/classificação}

Como já avaliado anteriormente, um dos problemas mais constantes para o caso em estudo é a queda de tubetes durante todo o processo, e, ainda nessa fase, os tubetes continuam a cair das bandejas, com a ressalva de que, nessa fase, estes estão ainda muito mais caros, pois, além de representarem um capital investido, foram agregados custos de mão-de-obra e materiais, como fungicidas e adubos, entre outros, e representam uma perda de mudas não prevista pelo planejamento, podendo contribuir para erros futuros.

Para a quantificação dos tubetes caídos foram separados dois dias de produção, que após o término foram coletados e contados.

Para uma produção total nos dois dias de avaliação, de 304.128 mudas, caíram 495 tubetes, equivalentes a $0,16 \%$.

Como essa operação ocorre de 20 a 30 dias após a saída da casa de vegetação, as estacas já devem ter recebido no mínimo quatro adubações e uma aplicação fúngica, avaliando-se daí quanto de trabalho já foi perdido. Os itens considerados como perda foram os seguintes: coleta de brotação, desinfecção de tubetes, enchimento de tubetes, encanteiramento, confecção de estacas, transporte de estacas para a casa de vegetação, estaqueamento, reencanteiramento e remoção/ classificação. Conforme apresentado no Quadro 3, esses itens representam um custo total de 67,87 R \$/MT.

Como o número de tubetes caídos, e conseqüentemente perdidos, é de $0,16 \%$ e o total dispendido é de 67,87 R \$/MM, tem-se que o custo de falha é igual a 0,10860 R\$/MM.

Não se deve esquecer de que esses são custos quantificáveis, mas transtornos causados pelos erros futuros, quanto a cumprimento de cronograma, custos de manutenção e quanto que aquela muda deixa de produzir por não se transformar numa árvore, entre outros, são de difícil quantificação.

\subsection{6. "Toilet"/classificação}

As porcentagenes de mudas fora do padrão observadas foram de $6,8 \%, 3,7 \%$ e $7,6 \%$, nas respectivas classes de tamanhos: grandes, médias e pequenas.

Considerando que as mudas grandes estão prontas para expedição e, portanto, não receberão mais nenhum tipo de seleção, pode-se concluir que $6,82 \%$ delas vão ao campo e não atendem aos padrões de qualidade estabalecidos pela própria empresa.

Como o custo de produção considerado é de 100,00 $\mathrm{R} \$ / \mathrm{MM}$, essa perda representa 6,82 R \$/MM. Além de gerar uma insatisfação ao pessoal envolvido no 
plantio, resultando em reclamações ao viveiro, o que pode potencializar conflitos internos na equipe da empresa, essas perdas serão maiores se as mudas, fora de especificações técnicas, forem plantadas, pois os custos de uma floresta de baixa produtividade são muito maiores, porém estes são de difícil quantificação.

Esse custo poderia ser considerado custo de falhas externas, porém como não foi realizada nenhuma avaliação externa ao viveiro e convencionou-se, para este trabalho, a utilização de custos de falhas totais, será assim considerado, apesar de o reflexo ser externo, pois nenhuma medida foi tomada no sentido de se corrigir o fato.

\subsection{Custos Totais da Qualidade}

Após os levantamentos realizados, quantificaramse os custos da qualidade por categoria, tendo sido obtida a distribuição apresentada no Quadro 4.

Percebe-se que os custos de falhas estão altos, e algo deve ser feito no sentido de reduzi-los ao mínimo. Jacovine et al. (1999), avaliando os custos da qualidade na colheita florestal semimecanizada, verificaram que a empresa não investia em avaliação e prevenção, tendo, consequientemente, altos custos de falhas. Tais custos chegaram a $\mathrm{R} \$ 1.538,91 / \mathrm{ha}$.

A partir dos componentes dos custos de falhas (Quadro 5), foi possível fazer a análise de Pareto. O gráfico de Pareto (Figura 1) permite identificar os principais itens que estão afetando a qualidade e quais devem ser priorizados na adoção de medidas para melhoria. No caso deste estudo, as medidas inicialmente a serem adotadas devem ser direcionadas à “Toilet”/Classificação, a qual representa $87,0 \%$ dos custos de falhas apurados. Após a minização dos custos de falhas desse item, devem-se dirigir esforços para o próximo, e assim por diante, até se chegar ao nível de custos da qualidade almejado.

Quadro 4-Classificação dos custos da qualidade em diferentes categorias

Table 4 -Classification of the quality costs in the different categories

\begin{tabular}{lcc}
\hline Categorias & Custo (R\$/MM) & Porcentagem $(\%)$ \\
\hline Prevenção & 5,12 & 39,5 \\
Avaliação & 0 & 0 \\
Falhas & 7,84 & 60,5 \\
\hline Total & 34,81 & 100,0 \\
\hline
\end{tabular}

Quadro 5 - Classificação dos custos de falhas para produção de mudas de Eucalyptus sp. por propagação vegetativa

Table 5 - Classification of flaw costs for the production of Eucalyptus sp. seedlings through vegetative propagation

\begin{tabular}{|c|c|c|c|}
\hline Fonte & $\begin{array}{l}\text { Valor } \\
(\mathrm{R} \$)\end{array}$ & $\begin{array}{c}\text { Frequência } \\
(\%)\end{array}$ & Acumulado \\
\hline Toilet/classificação & 6,82000 & 86,99 & 86,99 \\
\hline Confecção de estacas & 0,70871 & 9,04 & 96,03 \\
\hline Encanteiramento & 0,15141 & 1,93 & 97,96 \\
\hline Remoção/classificação & 0,10860 & 1,39 & 99,35 \\
\hline Enchimento de tubetes & 0,05118 & 0,65 & 100,00 \\
\hline
\end{tabular}

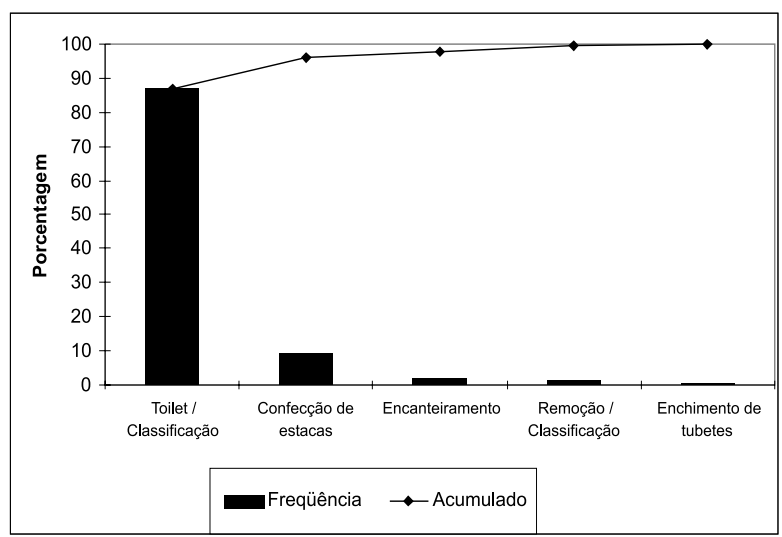

Figura 1 - Gráfico de Pareto para os custos de falhas do processo de produção de mudas de Eucalyptus spp. por propagação vegetativa.

Figure 1 -Pareto's graph for the costs of production flaws of Eucalyptus spp. seedlings through vegetative propagation.

Apesar de qualitativamente essa operação possuir baixo porcentual de falhas e apresentar-se sob controle (Figura 1), ela representa o maior custo de falhas. Por isso, a importância de se analisarem as avaliações como um todo e não compartimentalizada.

Os custos de prevenção representam $39,51 \%$ do total levantado. Segundo Juran e Gryna (1991), esses custos devem ser entre 10 e $50 \%$ do custo total da qualidade. Dessa forma, infere-se que os custos de prevenção estão em um bom patamar.

\section{CONCLUSÃO}

A partir dos resultados do estudo de caso, podese inferir que:

- Apesar de os investimentos em prevenção para a qualidade se encontrarem num bom patamar, os custos

R. Árvore, Viçosa-MG, v.29, n.6, p.955-964, 2005 
de falhas estão altos. Isso pode ser atribuído à falta de avaliação, que impede a determinação do grau de conformidade das várias operações que compõem o processo de produção de mudas, aliado à falta de investimentos em alguns pontos estratégicos de prevenção, como treinamento para a qualidade.

- Os custos de falhas em relação ao custo das mudas representam apenas $7,8 \%$. Esse valor é relativamente baixo, considerando-se a ausência de investimentos em avaliação e em treinamento de pessoal operacional. Esse mérito pode ser atribuído à alta qualificação do corpo técnico e aos investimentos em pesquisa.

- Apesar de esse valor parecer pequeno, quando se extrapola para o programa anual de 10 milhões de mudas e dependendo do custo real da produção, ele pode representar um valor absoluto considerável.

\section{AGRADECIMENTOS}

À CAPES (Coordenação de Aperfeiçoamento de Pessoal de Nível Superior), pela concessão da bolsa de mestrado, e ao Programa de Pós-Graduação em Ciência Florestal da Universidade Federal de Viçosa.

\section{REFERÊNCIAS BIBLIOGRÁFICAS}

DOUCHY, J. M. Em direção ao "zero defeito" na empresa. Tradução de Carmen Dolores Straube. São Paulo: Atlas, 1992. 189p.

GONÇALVES, E.O. et al. Avaliação qualitativa de mudas destinadas à arborização urbana no estado de Minas Gerais. Revista Árvore, v.28, n.4, p. 479-486, 2004.

JACOVINE, L.A.G. et al. Descrição e uso de uma metodologia para avaliação da qualidade na colheita florestal semi-mecanizada. Ciência Florestal, v.9, n.1, p. 143-160, 1999.

JURAN, J. M.; GRYNA, F. M. Controle de qualidade handbook. Tradução de Maria Cláudia de Oliveira Santos. São Paulo: Makron Books, McGraw-Hill, 1991. v. 1. 377p.

PAIVA, H. N.; GOMES, J. M. Viveiros

florestais. Viçosa, MG: Universidade Federal de Viçosa, 1995. 56 p.

ROBLES JR., A. Custos da qualidade, uma estratégia para a competição global. São Paulo: Atlas, 1994. 135p. 